\title{
FACTORS AFFECTING THE SHARE OF FAKE NEWS ABOUT COVID-19 OUTBREAK ON SOCIAL NETWORKS IN VIETNAM
}

\author{
Nguyen Nghi Thanh \\ Hanoi University of Home Affairs, Hanoi, Vietnam \\ ORCID iD: https://orcid.org/0000-0002-0791-8063 \\ thanhnndhnv@gmail.com

\section{Phuong Huu Tung*} \\ Hanoi University of Home Affairs, Hanoi, Vietnam \\ ORCID iD: https://orcid.org/0000-0003-0242-3448 \\ phuonghuutung@gmail.com
}

\section{Nguyen Hoai Thu}

Hanoi University of Home Affairs, Hanoi, Vietnam ORCID iD: https://orcid.org/0000-0002-6105-0365 nhthu3@gmail.com

\section{Pham Dinh Kien}

Hanoi University of Home Affairs, Hanoi, Vietnam ORCID iD: https://orcid.org/0000-0001-8757-7141 phamdinhkien2004@gmail.com

\section{Nguyen Anh Nguyet}

Hanoi University of Home Affairs, Hanoi, Vietnam ORCID iD: https://orcid.org/0000-0002-8912-9104 nguyetna.tckhnv@gmail.com

Abstract: In recent days in Vietnam, the amount of fake news spreading online about the Covid-19 epidemic has shown signs of increasing, causing information confusion and complicating the situation. This fact has received significant attention from scientists. To supplement the evidence of previous studies, enrich the research literature and make policy recommendations to the Government, this study explores the factors influencing the sharing of fake news on social networks. This study was conducted through a cross-sectional survey using an intentional sampling technique $(n=200)$ multivariate linear regression analysis technique was applied to prove the hypotheses. Research results show that the factors of altruism, entertainment, socialization, self-promotion, and instant information sharing have a positive and meaningful impact on sharing fake news about Covid_19 on social networks.

Keywords: Altruism; Instant News; Self-Promotion; Socialization; Fake News; Covid-19; Entertainment; Vietnam 


\section{INTRODUCTION}

The World Health Organization (WHO) has stressed that misinformation spreads rapidly through social media and poses a severe threat to the Covid-19 response. A person's trust in online information and perceived information overload are strong predictors of unverified information sharing to reduce the spread of Covid-19 misinformation and cyber disease, and measures should be taken to promote healthy skepticism about health news while protecting against information overload (Laato et al. 2020). Social media plays a vital role in pandemics like Covid-19, as it allows people to share news and personal experiences and perspectives with each other in real-time, globally. However, the various uses of social media lead to problematic consequences namely increased sharing of misinformation (Islam, Laato, Talukder, and Sutinen 2020). During the early stages of the Covid-19 outbreak, they are raising the response rate of the media reporting on the severity of Covid-19 and raising the response rate of public awareness to media reports. Besides improving medical literacy, media coverage can be an effective way to reduce disease spread in the early stages of an outbreak (Zhou, Wang, Xia, Xiao, and Tang 2020).

Fake news in journalism is not new; neither is confirmed the news that undermines trust in journalism (McNair 2017). Social media is a double-edged sword. On the one hand, low cost, easy access, and rapid dissemination of information make people search and view news from social media. On the other hand, it allows the widespread dissemination of 'fake news', i.e. low-quality news with purposeful misinformation. The widespread fake news can negatively impact individuals and society (Shu, Sliva, Wang, Tang, and Liu 2017). The problem is that information literacy is more helpful in preventing misinformation than the concepts of digital literacy, media literacy, and digital literacy about the news. Information literacy skills with information verification and backed by scientific knowledge can recognize Covid-19 misinformation, preventing individuals from believing possible misinformation leads to errors in action. Dissemination of scientific information requires practical intervention with the public, one of which is through the role of educational institutions (Khan and Idris 2019). Social media users' motivations for information sharing, socialization, information seeking, and time passing predicted the sharing of Covid-19 misinformation (Tasnim, Hossain, and Mazumder 2020). In Vietnam, over the past time, the spread of fake news and false information about the pandemic and the prevention and control of the Covid-19 has shown signs of increasing, with the main focus on inciting regions, dividing the significant national unity bloc; spreading false information about the effectiveness of Covid-19 vaccines, misrepresenting the government's vaccine allocation and supply policy, the use of the Covid-19 Vaccine Fund; disease developments in hot spots such as Ho Chi Minh City and southern provinces; misrepresenting the pandemic prevention and control measures of the government and localities. Much of the information comes 
from video clips of people in quarantine; people in the area are isolated and blocked. The appearance of malicious information and many 'spontaneous' video clips that are widely distributed in cyberspace has reduced people's confidence in disease prevention and control, causing confusion and anger in public opinion. This fact requires quantitative research to uncover why people share news on social media. Through usage and satisfaction theory, we investigate the factors that influence the intention to share fake news about Covid-19 on social media, thereby having policy implications for the Vietnamese government.

\section{LITERATURE REVIEW}

Many factors affect the spread of fake information in general and fake information about Covid-19 in particular. Based on the research of Apuke and Omar (2020), we identify the following factors that influence the spread of fake news about Covid 19 on social networks.

Altruism

Altruism became the significant positive driver of information-sharing intentions on Facebook (Plume and Slade 2018) influence on information sharing, spontaneous acquisition of knowledge from members (Fang and Chiu 2010), buoyant, direct, and significant impact on the online knowledge sharing (Ma and Chan 2014), affect on emotion and relevance and the intention to give advice or warning is the cause of spreading fake news (Duffy, Tandoc, and Ling 2019). Based on these findings, we will explore whether, in Vietnam, people share news about Covid-19 on social media because they enjoy helping others and feel like they can help those who need help others solve their problems, want to inspire and encourage others, want to inform others and advise others or not.

\section{Entertainment}

Entertainment factors on enjoyment and interpersonal connectivity predict social media use (Mäntymäki and Islam 2016; Rieger and Klimmt 2019; Vuori and Okkonen 2012). With the current pandemic, we are more isolated than ever. It can affect our psychological health and sense of community. Social media and electronic platforms provide a solution to this problem. Thus, members of the younger generation often share humor and laughter electronically (Chiodo, Broughton, and Michalski 2020; Islam, Laato, Talukder, and Sutinen 2020; Lee, Ma, and Goh 2011). Based on these findings, we will explore whether people share stories about Covid-19 on social networks in Vietnam because it is entertaining, funny, exciting, and refreshing. 
The socialization factor affecting news sharing on social networks has become a phenomenon of increasing social, economic, and political importance as individuals can now participate in product news and spread it in vast global virtual communities. Information-seeking, socializing, and status-seeking joy are more likely to share news on social media platforms (Lee and Ma 2012; Chang, Liu, and Shen 2017), socialization is a significant predictor of attitudes towards news sharing (Sihombing 2017; Lee, Ma, and Goh 2011). Technology user motivations and the social circumstances that users choose and using technology are helpful to fully understand the dynamics of choosing and using a particular technology to share information (Park and Chung 2012; Wasserman and Madrid-Morales 2019; Karnowski, Leonhard, and Kümpel 2018). Based on these findings, we explore the question of whether, in Vietnam, people share stories about Covid-19 on social media because talking about something with others feels be relevant to what is going on with others, can interact with others effectively by sharing news and exchanging ideas with others, and helping to stay in touch with others.

Self-Promotion

Self-promotion increases the sharing of misinformation (Islam, Laato, Talukder, and Sutinen 2020; Thompson, Wang, and Daya 2019). Self-promotional people motivated by information-seeking, socializing, and status-seeking pleasures are more likely to share news on social media platforms (Lee and Ma 2012; Islam, Mäntymäki, and Benbasat 2019; Talwar, Dhir, Kaur, Zafar, and Alrasheedy 2019).

Based on these findings, we explore whether, in Vietnam, people share stories about Covid-19 on social media because it helps impress others and helps selfexpression feel essential, and helps convey the desired image of them.

Instant News Sharing

People biased towards instant information sharing are positive towards fake news sharing due to lack of time (Talwar, Dhir, Singh, Virk, and Salo 2020; Tandoc, Jenkins, and Craft 2018; Chen, Sin, Theng and Lee 2015). Based on these findings, we explore the question of whether, in Vietnam, people immediately share stories about Covid-19 on social media because it can be helpful to others, to receive feedback on information found, to provide instant information, to share practical knowledge or skills with others, and to disseminate information that may be of interest to others. 
Building on research by Chadwick and Vaccari (2019) and Talwar et al. (2019), we will explore the question of whether participants share news on social networks mediated by Covid-19, which later turned out to be a hoax, fabricated, exaggerated at the time of sharing, did not check facts through reliable sources and did not verify its authenticity. With the research overview, the authors have built a research model about what is shown in Figure 1.

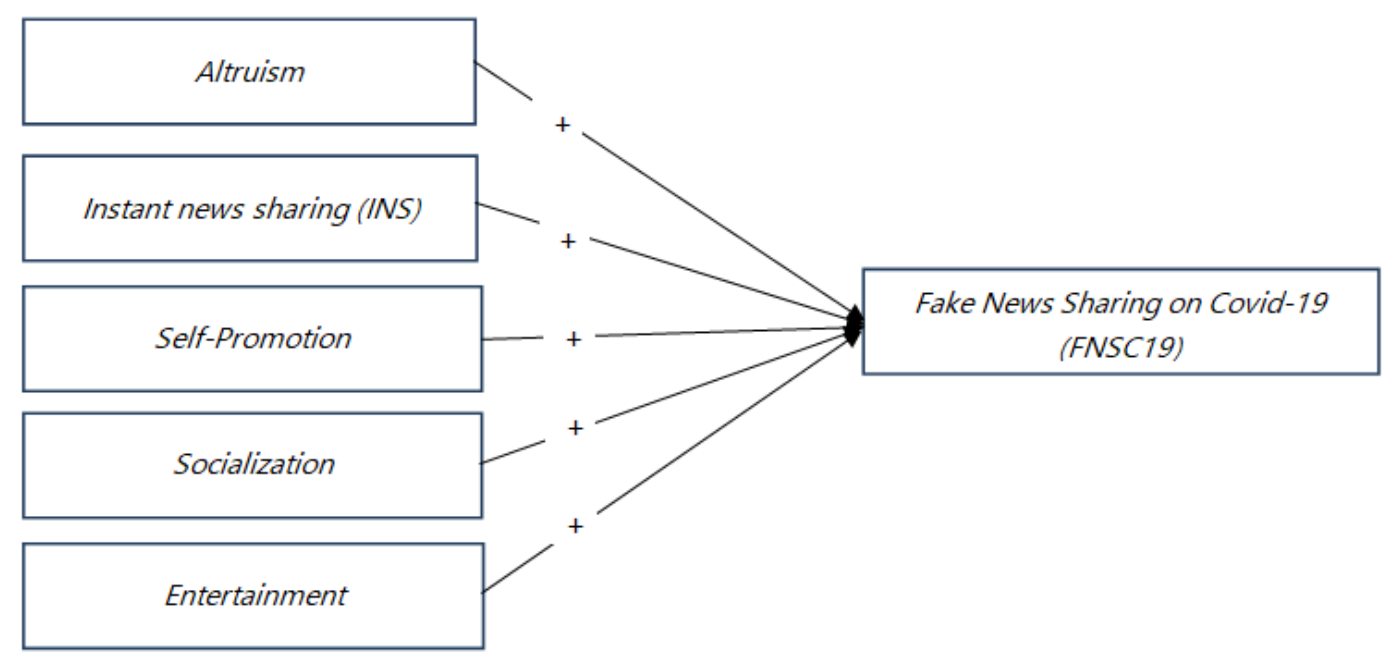

Figure 1: The Research Model (Source: Chadwick and Vaccari 2019)

\section{HYPOTHESES}

Based on the research model, the following hypotheses were formed:

$\mathrm{H} 1$ : The factor of altruism has a positive and meaningful impact on fake news sharing on Covid-19

H2: The instant news sharing factor has a positive and meaningful impact on fake news sharing on Covid-19

H3: The self-promotion factor has a positive and meaningful impact on fake news sharing on Covid-19

H4: The socialization factor has a positive and meaningful impact on fake news sharing on Covid-19

H5: The entertainment factor has a positive and meaningful impact on fake news sharing on Covid-19 


\section{METHODOLOGY}

Research Samples and Methods

To carry out this study, the authors conducted a survey, collecting opinions of the study participants in two steps: preliminary investigation and formal investigation.

\section{Preliminary Investigation}

The research team used a qualitative method by in-depth interviews with educational and psychologist researchers to adjust the research scale and improve the questionnaire to suit the characteristics of the survey area.

The questionnaire was built based on the results of the research overview and experts' opinions, including two parts. Part 1 collects demographic information of study participants such as age, gender, and occupation. Part 2 collects information about spreading fake information about Covid-19 on social networks. The month built by Apuke and Omar (2020) includes 28 items divided into 6 factors including Altruism $=5$ items, Instant News Sharing (INS) $=5$ items, Self-Promotion $=4$ items, Socialisation $=5$ items, Entertainment $=4$ items, and Fake News Sharing on Covid-19 $=5$ items.

The English questionnaire was translated into Vietnamese by two professional interpreters. A single Vietnamese version was created after discussion and final consensus between the translators and the principal investigator. A bilingual professional expert in public health contributed to this version to create a final version. This final version was pre-tested on 40 participants selected to represent age, sex, and occupation demographically.

During the assessment, participants were asked to complete this final version. Minor corrections followed to improve the question structure for better understanding, and the final Vietnamese version was completed using the official survey.

\section{Official Investigation}

Officially participating in the study were adults living in Hanoi who have been using social networks for a long time. The study period is July 2020. The questionnaire was sent directly to the respondents by non-random sampling method by email. As a result, 200 good votes were obtained, achieving a response rate of 100\% demographic information of study participants (Table 1). 
Table 1: Demographic Characteristics of Survey Participants (Source: Authors' specification)

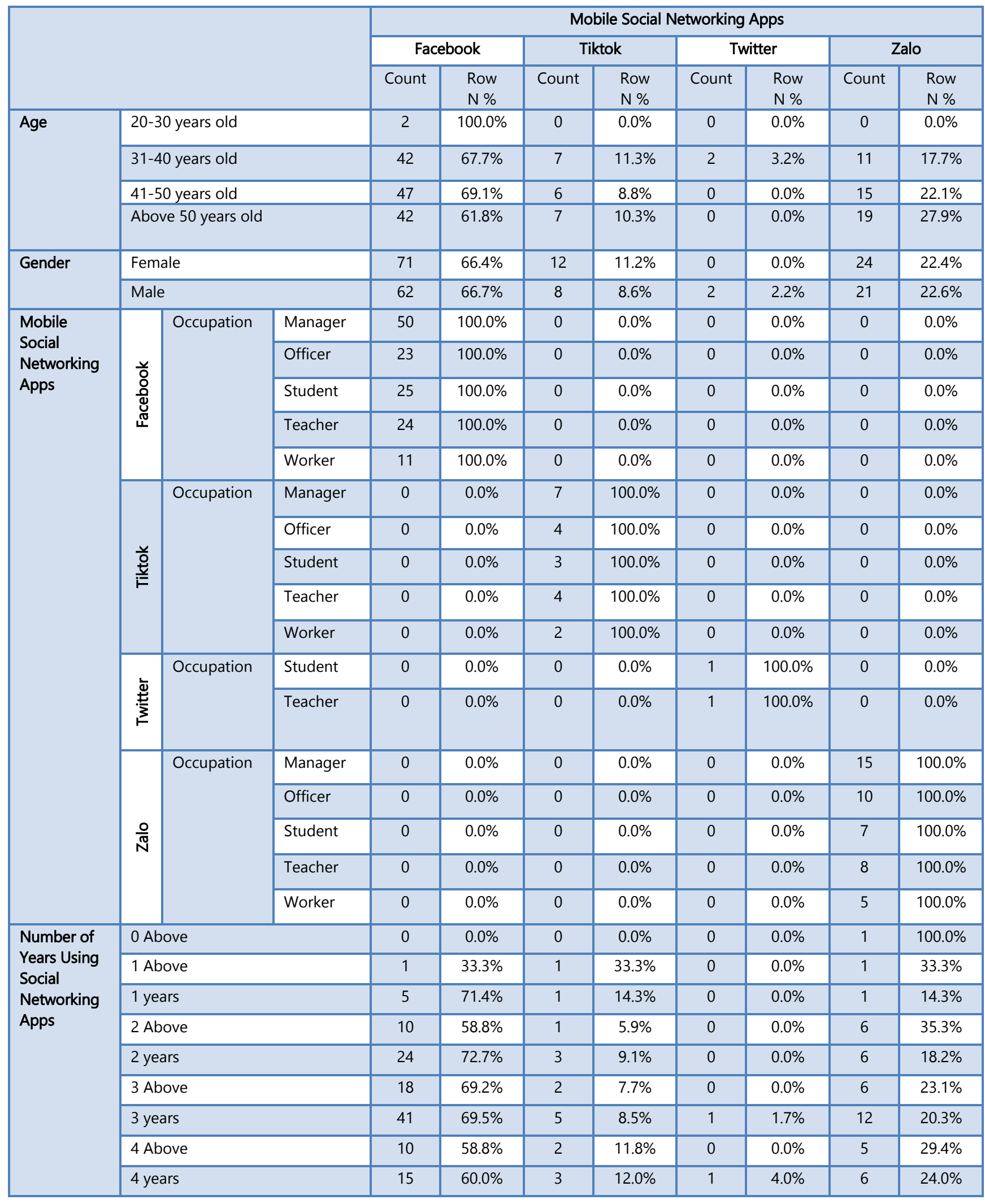




\begin{tabular}{|l|l|c|c|c|c|c|c|c|c|}
\hline & 5 Above & 2 & $100.0 \%$ & 0 & $0.0 \%$ & 0 & $0.0 \%$ & 0 & $0.0 \%$ \\
\cline { 2 - 10 } & 5 years & 5 & $83.3 \%$ & 0 & $0.0 \%$ & 0 & $0.0 \%$ & 1 & $16.7 \%$ \\
\cline { 2 - 10 } & 6 Above & 1 & $50.0 \%$ & 1 & $50.0 \%$ & 0 & $0.0 \%$ & 0 & $0.0 \%$ \\
\cline { 2 - 9 } & 6 years & 1 & $50.0 \%$ & 1 & $50.0 \%$ & 0 & $0.0 \%$ & 0 & $0.0 \%$ \\
\hline
\end{tabular}

\section{RESULTS}

The $R$ Programming language is used to analyze the reliability of the scale and the discovery factor. The analysis results suggest removing and merging some observed variables to help the scale evaluate concepts more accurately.

\section{Analyzing the Reliability of the Scales}

They are testing the scales through Cronbach's Alpha reliability coefficient to identify and remove junk variables to avoid creating misleading factors when analyzing exploratory factor analysis. Cronbach's Alpha coefficient has a variable value in the interval $[0,1]$. If a measurement variable has a total correlation coefficient of Corrected Item - Total Correlation $\geq 0.3$, that variable meets the requirements (Cronbach 1951; Taber 2018). The verification criterion is that the Cronbach's Alpha coefficient must be greater than 0.6, and the correlation coefficient of the sum variable in each scale must be greater than 0.3 (Hair, Black, Babin, and Anderson 2010). Table 2 shows that the scales of the factors are all standard. Therefore, all the scales of the factors are reliable and used for subsequent factor analysis. The Fake news sharing on the COVID-19 factor alone was excluded from the model because of Cronbach Alpha $<0.500$.

Table 2: Summary of Reliability and Relative Minimum Variables of Scales (Source: Authors' calculations)

\begin{tabular}{|l|c|c|c|}
\hline \multicolumn{1}{|c|}{ Scales } & $\begin{array}{c}\text { Number of } \\
\text { Variables } \\
\text { Observed }\end{array}$ & $\begin{array}{c}\text { Reliability Coefficients } \\
\text { (Cronbach Alpha) }\end{array}$ & $\begin{array}{c}\text { The Correlation Coefficient of the } \\
\text { Smallest Total Variable }\end{array}$ \\
\hline Altruism & 5 & 0.826 & 0.589 \\
\hline Instant News Sharing (INS) & 5 & 0.798 & 0.563 \\
\hline Self-Promotion & 4 & 0.769 & 0.552 \\
\hline Socialisation & 5 & 0.790 & 0.495 \\
\hline Entertainment & 4 & 0.786 & 0.567 \\
\hline $\begin{array}{l}\text { Fake News Sharing on COVID-19 } \\
\text { (FNSC19) }\end{array}$ & 5 & 0.813 & 0.542 \\
\hline
\end{tabular}

After testing Cronbach's Alpha, the author uses exploratory factor analysis (EFA) to preliminary evaluate the scales' unidirectional, convergent, and discriminant values. EFA was used by extracting the Principal Components Analysis Factor and Varimax 
rotation to group the factors. With a sample size of 200, the factor loading factors of the observed variables must be greater than 0.5 ; variables converge on the same factor and are distinguished from other factors. In addition, the Kaiser-Meyer-Olkin coefficient (KMO) is an index used to consider the adequacy of factor analysis that must be in the range $0.5 \leq \mathrm{KMO} \leq 1$ (Cerny and Kaiser 1977; Kaiser 1974). The analysis results in Table 3 show that all factor loading coefficients of the observed variables are greater than 0.5; Bartlett test with Sig meaning. $=0.000$ with $\mathrm{KMO}$ coefficient $=0.88$. All 28 items using EFA are extracted into six factors with Eigenvalues greater than one and Cumulative variance percent $=61 \%$. Thus, the research model consisting of 5 independent variables and one dependent variable is used for linear regression analysis and subsequent hypothesis testing.

Table 3: Exploratory Factor Analysis (Source: Authors' calculations)

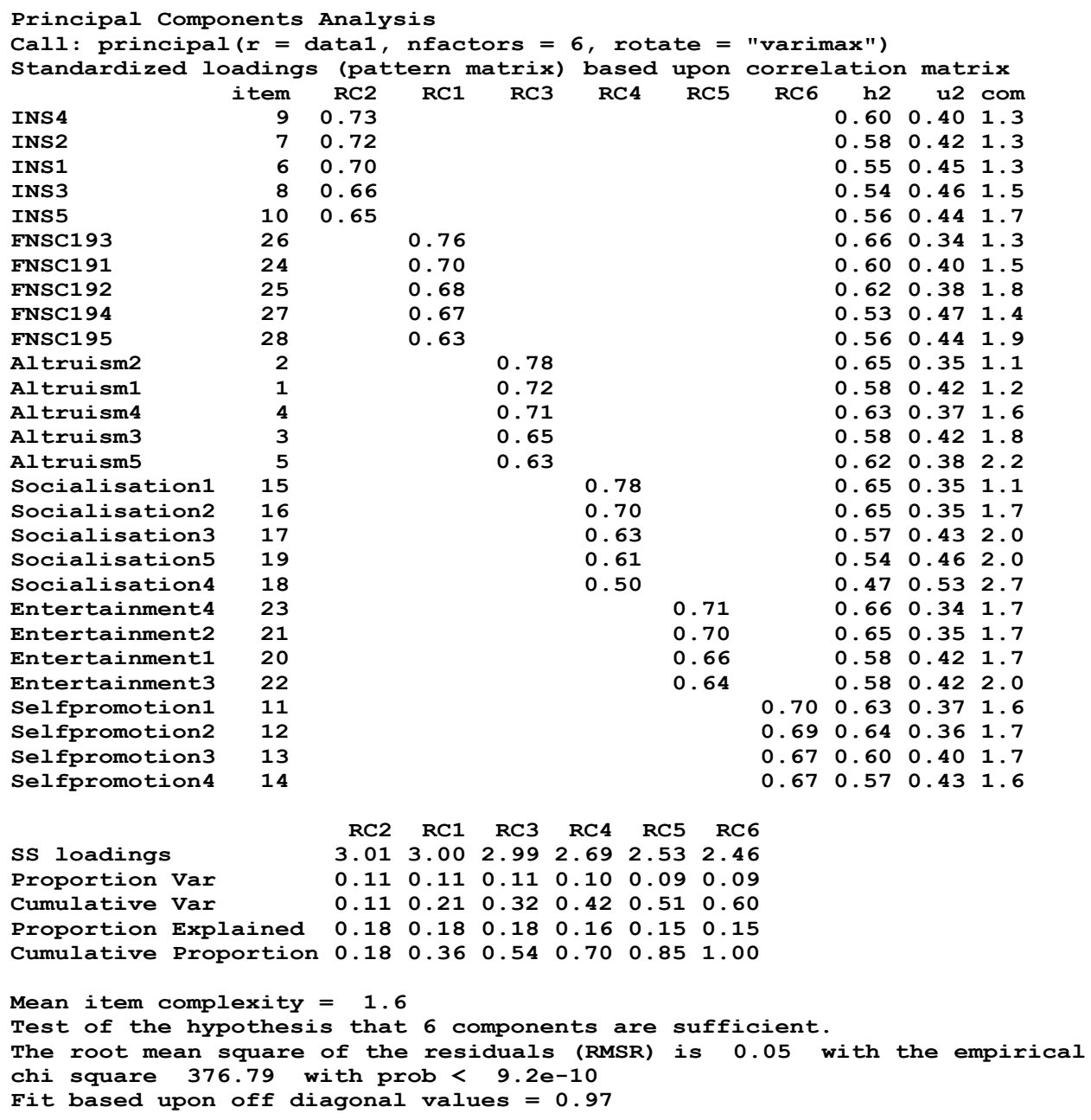




\section{Pearson Correlation Analysis}

The author uses Pearson correlation analysis to analyze the correlation between quantitative variables. Figure 2 shows that, at the $5 \%$ level of significance, the correlation coefficient shows that the relationship between the dependent and independent variables is statistically significant (Sig. $<0.05$ ). The magnitude of the correlation coefficients ensures that multicollinearity does not occur. Therefore, other statistics can be used to verify the relationship between variables.

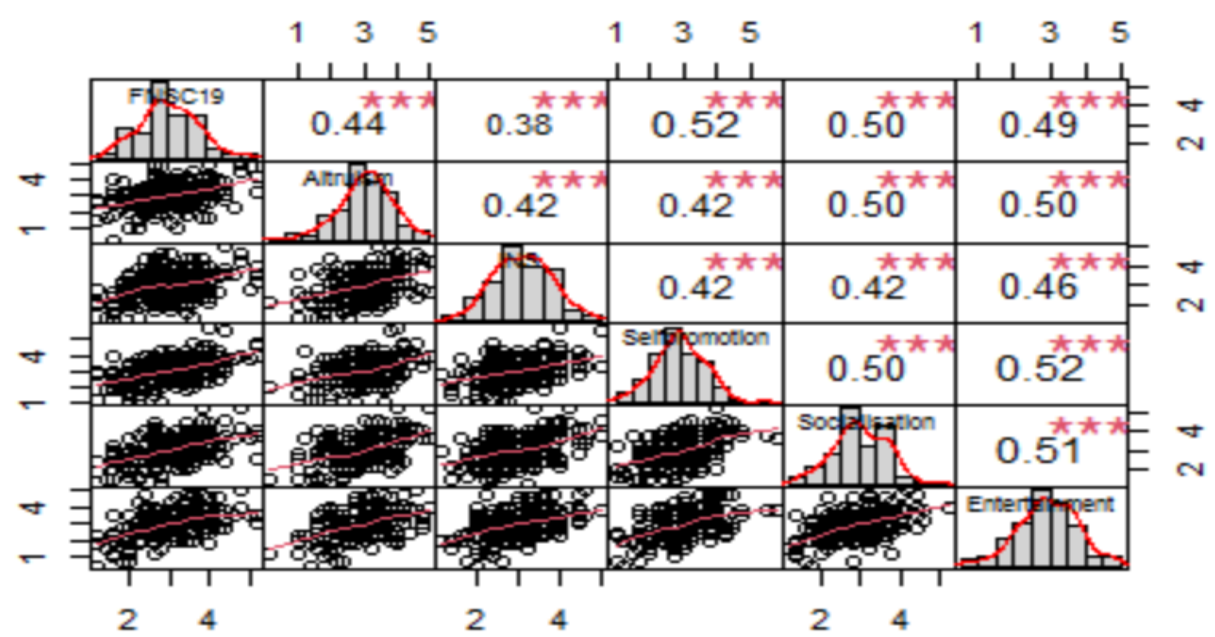

Figure 2: Pearson Correlation Analysis Results (Source: Authors' calculations)

\section{Regression Analysis}

The authors conduct a multivariable linear regression analysis on the relationship between 5 independent variables: Altruism, INS, Self-Promotion, Socialisation, and Entertainment, and one dependent variable, FNSC19. Table 4 shows that the mode has $\mathrm{R} 2=0.394$, showing that the built linear regression model fits the data set. The results show that all five independent variables have a positive and significant impact on the dependent variable. Table 4 shows that, with $95 \%$ confidence, the hypotheses proposed by the research team are accepted. Specifically, the variable Self_promotion has the most substantial effect on the variable FNSC19 with $\beta=0.265$, the variable Entertainment with $\beta=0.161$, the variable Altruism with $\beta=0.124$. The weakest effect is the variable INS with $\beta=0.062$. With this result, the hypotheses proposed by the research team are accepted. 
Table 4: The Results of Multiple Linear Regression Analysis (Source: Authors' calculations)

\begin{tabular}{|c|c|}
\hline & $\begin{array}{c}\text { Dependent variable: } \\
\text { FNSC19 }\end{array}$ \\
\hline Altruism & $\begin{array}{l}0.124 * \\
(0.069)\end{array}$ \\
\hline INS & $\begin{array}{l}0.062 \\
(0.074)\end{array}$ \\
\hline Selfpromotion & $\begin{array}{r}0.265 \star \star \star \\
(0.071)\end{array}$ \\
\hline Socialisation & $\begin{array}{l}0.215 \star \star \star \\
(0.078)\end{array}$ \\
\hline Entertainment & $\begin{array}{l}0.161 * \star \\
(0.073)\end{array}$ \\
\hline Constant & $\begin{array}{l}0.505 * \star \\
(0.238)\end{array}$ \\
\hline Observations & 200 \\
\hline $\begin{array}{l}\text { R2 } \\
\text { Adjusted R2 }\end{array}$ & $\begin{array}{l}0.394 \\
0.378\end{array}$ \\
\hline $\begin{array}{l}\text { Residual Std. Error } \\
\text { F Statistic }\end{array}$ & $\begin{aligned} 0.648 & (\mathrm{df}=194) \\
25.179 * \star * & (\mathrm{df}=5 ; 194)\end{aligned}$ \\
\hline
\end{tabular}

\section{CONCLUSION}

The results show that all five factors (Altruism, Instant News Sharing, Selfpromotion, Socialisation) positively and significantly impact fake news sharing on Covid19. This result is similar to the finding of (Apuke and Omar 2020). Notably, the Selfpromotion and Socialisation factors have the most substantial impact on fake news sharing on Covid-19. The factors Entertainment, Altruism affect the factor fake news sharing on Covid-19 to a lesser extent. Finally, the factor INS has the weakest impact on the variable fake news sharing on Covid-19. From this result, the research team made the following:

Firstly, the spread of fake news about Covid-19 in Vietnam in recent years has been most strongly influenced by two factors of Self-promotion and Socialization factor, secondly, by the Entertainment factor and Altruism factor. The weakest effect is the INS factor. This result goes against the qualitative articles published in Vietnam in the past, which have focused on causes such as likes, fraud, and political factors against the Vietnamese government's anti-epidemic method. 
Second, official Covid_19 information needs to be shared widely to the public domain through social media. It will reduce the spread of fake news about cure and prevention tips found online (Apuke and Omar 2020). Official information was the most vital driver in predicting news-sharing intentions, followed by socialization and statusseeking (Lee, Ma, and Goh 2011).

Third, social media plays a vital role during pandemics like Covid-19, as it allows people to share news and personal experiences and views with each other in real-time, globally is undeniable. However, the various uses of social media lead to problematic consequences namely increased sharing of misinformation (Islam, Laato, Talukder, and Sutinen 2020). The model we propose above predicts the sharing of misinformation about Covid-19 in Vietnam.

Fourth, the Government of Vietnam needs to focus on communicating information literacy skills and how to verify scientific information to recognize misinformation about COVID-19 so that it can prevent individuals from believing it. Misinformation can lead to errors in anti-pandemic action. Disseminating scientific information about Covid_19 requires practical intervention with the public, one of which is through the role of educational institutions (Khan and Idris 2019).

In short, in Vietnam, people share news about Covid-19 on social media because they like to support others, feel they can help others with their problems, want to inspire and encourage others, wanting to inform others, and advise others. In addition, people share stories about Covid-19 on social media. They are entertaining, funny, engaging, and refreshing because they want to talk about something and feel connected to other people about what is going on with others. They want to interact with others when sharing news, effectively exchanging ideas with others, and help to stay in touch with others.

People are also sharing stories about Covid-19 on social media because it helps impress others, helps express themselves, feels essential, helps convey the desired image of themselves to others. Because it means it can be helpful to others, share news to get feedback on the information they have found, provide instant information to others, share knowledge or skills practical ability with others, and disseminate information that may be of interest to others.

As with other empirical studies, there are limitations to this study that should be considered when discussing the results. First, our survey method reflects the subjective perception of the respondents towards the questions being investigated. Subjective data has some inherent disadvantages that are hard to avoid in surveys (Pakpour, Gellert, Asefzadeh, Updegraff, Molloy, and Sniehotta 2016). Our data is collected over a single period. Cross-sectional data do not allow a dynamic assessment of changes in students' intentions and related behaviors regarding their college admissions, affecting their applicability (Xin, Liang, Zhanyou, and Hua 2019). Future research should combine cross-sectional and longitudinal studies. 
The intentional sampling method has certain limitations, not fully reflecting population characteristics (Lin et al. 2016; Strong et al. 2018). Our survey was conducted within a cultural context of Vietnam and therefore requires more general statements that can be made by applying the development research model and research conclusions to other countries and cultures (Sun et al. 2012). Moreover, R2 $=0.394$ should affect the research results. In future research, R2 will be improved by increasing sample size and further diversifying study participants. 


\section{ACKNOWLEDGMENTS}

Hanoi University of Home Affairs funded this research. The authors sincerely thank the student community of Hanoi University of Home Affairs for supporting the survey. 


\section{REFERENCES}

1. Apuke, Oberiri \& Omar, Bahiyah. (2020). User motivation in fake news sharing during the COVID-19 pandemic: an application of the uses and gratification theory. Online Information Review, 45,220-239. 10.1108/OIR-03-2020-0116.

2. Chang, S.E., Liu, A.Y., and Shen, W.C. (2017). User trust in social networking services: a comparison of Facebook and Linkedln. Computers in Human Behavior, 69, 207-217, doi: 10.1016/j. chb.2016.12.013.

3. Chen, X., Sin, S.C.J., Theng, Y.L. and Lee, C.S. (2015). Why students share misinformation on social media: motivation, gender, and study-level differences. The Journal of Academic Librarianship, 41(5), 583-592, doi: 10.1016/j.acalib.2015.07.003.

4. Chiodo, C.P., Broughton, K.K. and Michalski, M.P. (2020). Caution: wit and humor during the COVID-19 pandemic. Foot and Ankle International, 41(6), 763-764, doi: 10.1177/ 1071100720923651

5. Duffy, A., Tandoc, E., and Ling, R. (2019). Too good to be true, too good not to share: the social utility of fake news. Information, Communication and Society, 115. doi: 10.1080/ 1369118X.2019.1623904

6. Fang, Y.H. and Chiu, C.M. (2010). In justice we trust: exploring knowledge-sharing continuance intentions in virtual communities of practice. Computers in Human Behavior, 26(2), 235-246, doi: 10.1016/j.chb.2009.09.005.

7. Islam, A.K.M.N., Laato, S., Talukder, S. and Sutinen, E. (2020). Misinformation sharing and social media fatigue during COVID-19: an affordance and cognitive load perspective. Technological Forecasting and Social Change, 159, 120201, doi: 10.1016/j.techfore.2020.120201.

8. Islam, A.K.M.N., Mäntymäki, M. and Benbasat, I. (2019). Duality of self-promotion on social networking sites. Information Technology and People, 32 (2), 269-296. doi: 10.1108/ ITP-07-2017-0213.

9. Karnowski, V., Leonhard, L. and Kümpel, Anna Sophie. (2018). Why users share the news: a theory of reasoned action-based study on the antecedents of newssharing behavior. Communication Research Reports, 35(2), 91-100. doi: 10.1080/08824096.2017.1379984.

10. Khan, M.L. and Idris, I.K. (2019). Recognize misinformation and verify before sharing: a reasoned action and information literacy perspective. Behavior and Information Technology, 1-19. doi: 10.1080/0144929X.2019.1578828

11. Laato, S., Islam, A.K.M.N., Islam, M.N. and Whelan, E. (2020). What drives unverified information sharing and cyberchondria during the COVID-19 pandemic?. European Journal of Information Systems, 23(3), 1-18. doi: 10.1080/0960085X.2020.1770632. 
12. Lee, C.S. and Ma, L. (2012). News sharing in social media: the effect of gratifications and prior experience. Computers in Human Behavior, 28 (2), 331 339. doi: 10.1016/j.chb.2011.10.002

13. Lee, C.S., Ma, L. and Goh, D.H.L. (2011). Why do people share news on social media?". Lecture Notes in Computer Science (Including Subseries Lecture Notes in Artificial Intelligence and Lecture Notes in Bioinformatics). 6890 LNCS, 129-140. doi: 10.1007/978-3-642-23620-4_17.

14. Ma, W.W.K. and Chan, A. (2014). Knowledge sharing and social media: altruism, perceived online attachment motivation, and perceived online relationship commitment. Computers in Human Behavior, 39, 51-58, doi: 10.1016/j.chb.2014.06.015.

15. Mäntymäki, Matti and Islam, A.K.M.N. (2016). The Janus face of Facebook: positive and negative sides of social networking site use. Computers in Human Behavior, 61, 4-26. doi: 10.1016/j. chb.2016.02.078.

16. McNair, B. (2017). Fake News: Falsehood, Fabrication, and Fantasy in Journalism. Routledge, London.

17. Park, N., Chung, J.E. and Lee, S. (2012). Explaining the use of text-based communication media: an examination of three theories of media use. Cyberpsychology, Behavior, and Social Networking, 15(7), 357-363. doi: 10.1089/cyber.2012.0121.

18. Plume, C.J. and Slade, E.L. (2018). Sharing of sponsored advertisements on social media: a uses and gratifications perspective. Information Systems Frontiers, 20 (3), 471- 483. doi: 10.1007/s10796-017-9821-8.

19. Rieger, D., \& Klimmt, C. (2019). The daily dose of digital inspiration 2: Themes and affective user responses to meaningful memes in social media. New Media \& Society, 21(10), 2201-2221. https://doi.org/10.1177/1461444819842875

20. Shu, K., Sliva, A., Wang, S., Tang, J. and Liu, H. (2017). Fake news detection on social media. ACM S/GKDD Explorations Newsletter,19(1), 22-36. doi: $10.1145 / 3137597.3137600$

21. Sihombing, S.O. (2017). Predicting intention to share news through social media: an empirical analysis in an Indonesian youth context. Business and Economic Horizons,13(4), 468-477, doi: 10.15208/beh.2017.32.

22. Talwar, S., Dhir, A., Kaur, P., Zafar, N., and Alrasheedy, M. (2019). Why do people share fake news? Associations between the dark side of social media use and fake news sharing behavior. Journal of Retailing and Consumer Services, 51, 72-82. doi: 10.1016/j. jretconser.2019.05.026.

23. Talwar, S., Dhir, A., Singh, D., Virk, G.S. and Salo, J. (2020). Sharing of fake news on social media: application of the honeycomb framework and the third-person effect hypothesis. Journal of Retailing and Consumer Services, 57, 102197. doi: 10.1016/j.jretconser.2020.102197. 
24. Tandoc, E.C., Jenkins, J. and Craft, S. (2018). Fake news as a critical incident in journalism. Journalism Practice, 13(6), 673-689. doi: 10.1080/17512786.2018.1562958.

25. Tasnim, S., Hossain, M. and Mazumder, H. (2020). Impact of rumors or misinformation on coronavirus disease (COVID-19) in social media, 1-6. doi: 10.31235/osf.io/uf3zn.

26. Thompson, N., Wang, X. and Daya, P. (2019). Determinants of news sharing behavior on social media. Journal of Computer Information Systems, 1-9, doi: 10.1080/08874417. 2019.1566803.

27. Vuori, V. and Okkonen, J. (2012). Knowledge sharing motivational factors of using an intra- organizational social media platform. Journal of Knowledge Management, 16(4), 592-603, doi: 10.1108/13673271211246167.

28. Wasserman, H. and Madrid-Morales, D. (2019). An exploratory study of 'fake news' and media trust in Kenya, Nigeria, and South Africa. African Journalism Studies, 3670, 1-17. doi: 10.1080/23743670.2019.1627230.

29. Zhou, W., Wang, A., Xia, F., Xiao, Y. and Tang, S. (2020). Effects of media reporting on mitigating the spread of COVID-19 in the early phase of the outbreak. Mathematical Biosciences and Engineering, 17(3), 2693-2707. doi: 10.3934/mbe.2020147. 